\title{
Commentary: Enough is enough, but when is enough enough?
}

Janet M. C. Ngu, MD, MSc, FRCSC, and

Fraser D. Rubens, MD, MSc, FACS, FRCSC

"You never know what is enough unless you know what is more than enough"

-William Blake (1757-1827)

The use of preoperative clopidogrel in patients with acute coronary syndrome (ACS) undergoing coronary artery bypass grafting (CABG) surgery has dogged the lives of cardiac surgeons. There is abundant evidence consistently showing that this strategy is associated with higher rates of bleeding and reopening, as well as other adverse events. ${ }^{1-3}$ In this issue of the Journal, Qu and colleagues ${ }^{4}$ present a well-executed retrospective study with a large sample size of 5543 patients. The authors used inverse probability weighting, which is a robust statistical analysis method to disconnect confounders and treatment. ${ }^{5}$ To no one's surprise, this study showed a significantly increased risk of the composite of major adverse cardiac and cerebrovascular events, major bleeding, and transfusion in patients with ACS and preoperative exposure of clopidogrel within 5 days of CABG. Most of these findings are not novel because they have been consistently demonstrated by numerous studies in the past, as summarized in Table E1 in this study. ${ }^{4}$

What was compelling for this reader was that the primary outcome of this study was predominantly driven by stroke, with most events presumed to be ischemic because only 2 patients had intracranial hemorrhages. This is counterintuitive because one would expect that the use of preoperative clopidogrel would reduce the risk of ischemic stroke because of its antithrombotic effect. The authors speculated that the increased risk of stroke in these patients could be a sequela of bleeding complications (reoperation and bleeding).

\footnotetext{
From the Division of Cardiac Surgery, University of Ottawa Heart Institute, Ontario, Canada.

Disclosures: The authors reported no conflicts of interest.

The Journal policy requires editors and reviewers to disclose conflicts of interest and to decline handling or reviewing manuscripts for which they may have a conflict of interest. The editors and reviewers of this article have no conflicts of interest..

Received for publication April 12, 2020; revisions received April 12, 2020; accepted for publication April 12, 2020; available ahead of print May 6, 2020.

Address for reprints: Fraser D. Rubens, MD, MSc, FACS, FRCSC, 40 Ruskin St, Ottawa, Ontario, Canada (E-mail: FRubens@ottawaheart.ca).

J Thorac Cardiovasc Surg 2022;163:1053-4

$0022-5223 / \$ 36.00$

Copyright (C) 2020 by The American Association for Thoracic Surgery

https://doi.org/10.1016/j.jtcvs.2020.04.053
}

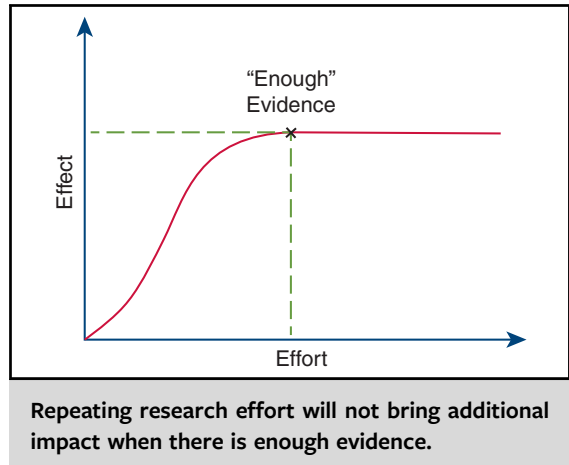

\section{CENTRAL MESSAGE \\ It is well established that preop- erative clopidogrel use in pa- tients with ACS undergoing CABG is associated with higher rates of complications. We need to move on.}

Regardless, the message is the same; clopidogrel should be discontinued preoperatively in patients with ACS undergoing CABG. Why is this not gaining traction? Are the current findings not anticipated or not justified based on what we already know at this time? Are we hoping if we keep repeating this natural experiment, the results might change? What are the factors that are preventing us from dealing with this?

We need to focus our attention and effort in developing individualized care for each patient. For example, development of specific risk-stratification tools and implementation of platelet function testing might help in determining the best timing to discontinue clopidogrel or any other antiplatelet agent in patients with ACS undergoing CABG. The duration of clopidogrel discontinuation should not be a merely arbitrary number that fits all patients. In addition, the role of intravenous antiplatelet agents with a shorter half-life as a means to transition to CABG should be encouraged.

As far as we are concerned, this issue has been answered. We hope the next questions address the mechanisms, not just of the adverse outcomes, but of our health systems that inefficiently repeat history.

\section{References}

1. Hansson EC, Jideus L, Aberg B, Bjursten H, Dreifaldt M, Holmgren A, et al. Coronary artery bypass grafting-related bleeding complications in patients treated with ticagrelor or clopidogrel: a nationwide study. Eur Heart J. 2016;37:189-97. 2. Ebrahimi R, Dyke C, Mehran R, Manoukian SV, Feit F, Cox DA, et al. Outcomes following pre-operative clopidogrel administration in patients with acute coronary 
syndromes undergoing coronary artery bypass surgery: the ACUITY (Acute Catheterization and Urgent Intervention Triage strategY) trial. J Am Coll Cardiol. 2009;53:1965-72.

3. Berger JS, Frye CB, Harshaw Q, Edwards FH, Steinhubl SR, Becker RC. Impact of clopidogrel in patients with acute coronary syndromes requiring coronary artery bypass surgery: a multicenter analysis. J Am Coll Cardiol. 2008;52:1693-701.
4. Qu J, Zhang D, Zhang H, Rao C, Chen S, Zhao Y, et al. Preoperative clopidogrel and outcomes in patients with acute coronary syndrome undergoing coronary artery bypass surgery. J Thorac Cardiovasc Surg. 2022;163:1044-52.e15.

5. Curtis LH, Hammill BG, Eisenstein EL, Kramer JM, Anstrom KJ. Using inverse probability-weighted estimators in comparative effectiveness analyses with observational databases. Med Care. 2007;45:S103-7.
See Article page 1044

\section{Commentary: Rushing to} revascularize may be risky, but one size does not fit all

\author{
Malak Elbatarny, MD, ${ }^{\mathrm{a}}$ Amr Alsalakawy, $\mathrm{MBChB},{ }^{\mathrm{b}}$
} and

Stephen E. Fremes, MD, MSc, FRCSC, FACP, FACC ${ }^{c}$

Optimal timing of coronary artery bypass grafting (CABG) in the context of acute coronary syndrome (ACS) and dual antiplatelet therapy remains controversial and practice patterns vary. Despite consensus among guidelines that minimum 5day preoperative clopidogrel cessation is ideal, ${ }^{1,2}$ risk of adverse events during the washout period is dependent on coronary anatomy. Further, baseline bleeding risk varies among patients and the evidence for optimal timing of CABG is mixed. ${ }^{3-5}$ Clopidogrel cessation decreases the risk for bleeding and resultant secondary complications, but comes at the cost of a potentially increased risk of recurrent myocardial infarction (MI) or other thrombotic events. We congratulate $\mathrm{Qu}$ and colleagues $^{6}$ for addressing this controversy.

Their study is a single-center retrospective observational analysis of 5543 patients undergoing post-ACS CABG.

From the ${ }^{\mathrm{a} D i v i s i o n}$ of Cardiac Surgery, Department of Surgery, University of Toronto, Toronto, Ontario, Canada; ' Division of Cardiac Surgery, Magdi Yacoub Foundation, Aswan Heart Centre, Aswan, Egypt; and ${ }^{\mathrm{c}}$ Schulich Heart Centre, Division of Cardiac Surgery, Department of Surgery, Sunnybrook Health Sciences Centre, University of Toronto, Toronto, Ontario, Canada.

Dr Fremes is supported by the Bernard S. Goldman Chair in Cardiovascular Surgery (University of Toronto).

Disclosures: The authors reported no conflicts of interest.

The Journal policy requires editors and reviewers to disclose conflicts of interest and to decline handling or reviewing manuscripts for which they may have a conflict of interest. The editors and reviewers of this article have no conflicts of interest.

Received for publication April 10, 2020; revisions received April 10, 2020; accepted for publication April 12, 2020; available ahead of print April 23, 2020

Address for reprints: Stephen E. Fremes, MD, MSc, FRCSC, FACP, FACC, Sunnybrook Health Sciences Centre, 2075 Bayview Ave, Room H4 05, Toronto, Ontario M4N 3M5, Canada (E-mail: stephen.fremes@sunnybrook.ca).

J Thorac Cardiovasc Surg 2022;163:1054-6

$0022-5223 / \$ 36.00$

Copyright (c) 2020 by The American Association for Thoracic Surgery

https://doi.org/10.1016/j.jtcvs.2020.04.051
Check for updates

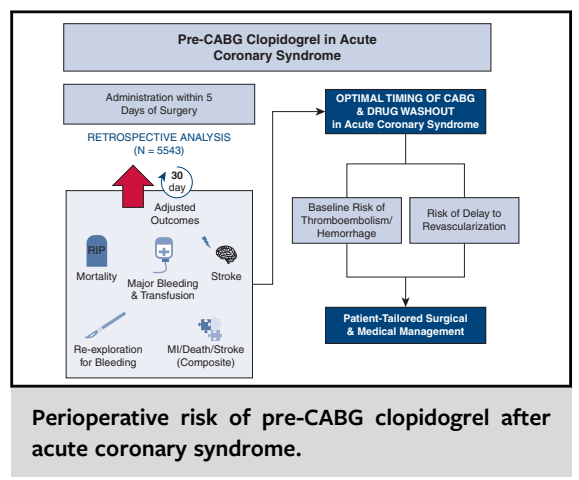

CENTRAL MESSAGE

Proceeding with CABG before clopidogrel washout is associated with adverse perioperative outcomes. Is this the place for patient-tailored decision making?

Using institutional registry data, the authors compared those receiving clopidogrel within 5 days of CABG $(\mathrm{n}=820 ; 15 \%)$ versus those for whom clopidogrel was stopped $>5$ days in advance $(n=4723 ; 85 \%)$. The primary outcome, a composite of stroke, all-cause mortality, and MI at 30 days, was worse, not better, in the late cessation group (odds ratio, 1.63; 95\% confidence interval, 1.16-2.29; $P=.005)$. The same pattern was seen in all secondary 30-day outcomes in descending order of effect size, including stroke, transfusion, major bleeding events (defined by validated CABG-specific bleeding criteria ${ }^{7}$ ), and re-exploration for bleeding. In other words, early cessation of clopidogrel was associated with both a reduction in bleeding and a reduction in thrombotic events. The authors implemented inverse probability treatment weighting to account for baseline differences and sensitivity analysis with propensity score matching reinforce the robustness of the findings. The small number of patients who did not undergo CABG due to cardiovascular events during the preoperative waiting period were also included 